\title{
HUBUNGANKECEMASAN IBU DENGAN PEMBERIAN IMUNISASI DASAR LENGKAP PADA BAYI USIA 0-12 BULAN DIDESA BANJAR BARAT KECAMATAN GAPURA
}

\author{
Sri Sumarni, Program Studi Ilmu Keperawatan Universitas Wiraraja \\ Email: sri.sumarni73@yahoo.com
}

\begin{abstract}
ABSTRAK
Imunisasi adalah suatu usaha memasukkan vaksin ke dalam tubuh yang akan membuat zat anti dengan tujuan mencegah terhadap penyakit tertentu, imunisasi kadang di takutkan oleh ibu karena evek samping yang terjadi setelah di berikan imunisasi sehingga ibu cemas, penyebab kecemasan ibu di karenakan pemberitaan miring tentang efek samping imunisasi. Penelitian ini bertujuan untuk mengetahui hubungan kecemasan ibu dengan pemberian imunisasi dasar lengkap pada bayi usia 0-12 bulan di Desa Banjar Barat Kecamatan Gapura.

Jenis penelitian ini merupakan analitik korelasional cross sectional study. Populasi dalam penelitian ini adalah semua ibu yang memiliki bayi usia 0-12 bulan sebanyak 35 ibu. Tehnik pengambilan sampel pada penelitian adalah Total Sampling. Sampel dalam penelitian ini adalah semua ibu yang memiliki bayi usia 0-12 bulan sebanyak 35 ibu. Pengumpulan data menggunakan kuesioner HARS (Hamilton Anxiety Rating Scale) dan observasi buku KIA. Analisa data yang digunakan adalah uji korelasi spearman dengan nilai signifikansi $p=0,05$.

Hasil penelitian didapatkan bahwa sebagian besar ibu mengalami kecemasan ringan sebanyak 22 ibu (62,9\%), dan sebagian besar ibu memberikan imunisasi dasar yang tidak lengkap sebanyak 19 orang (54,3\%). Hasil uji statistik diperoleh $P$ value $<\alpha(0,000<0,05)$ dan tingkat kepercayaan 95\%. Kekuatan korelasi adalah $r$ sebesar 0,732 yang berarti ada hubungan yang signifikan antara kecemasan ibu dengan pemberian imunisasi dasar lengkap pada bayi usia 0-12 bulan di Desa Banjar Barat kecamatan Gapura.

Sehingga kepada para ibu yang memiliki bayi usia 0-12 bulan perlu adanya ikut serta jika ada penyuluhan kesehatan mengenai imunisasi dasar lengkap dan banyak bertanya sebelum di lakukan pemberian imunisasi pada bayinya
\end{abstract}

Kata kunci : kecemasan ibu, pemberian imunisasi dasar lengkap

\section{Pendahuluan}

Tidak tercapainya pemberian imunisasi dasar lengkap masih banyak di jumpai di indonesia. Salah satu faktor di sebabkan karena kecemasan keluarga. Imunisasi merupakan suatu usaha memberikan kekebalan pada bayi dan anak dengan memasukkan vaksin kedalam tubuh agar tubuh membuat zat anti untuk mencegah terhadap penyakit tertentu. (A.Aziz Alimul Hidayat, hal 101.) Sedangkan yang di maksud vaksin adalah bahan yang di pakai untuk merangsang pembentukan zat anti yang di masukkan ke dalam tubuh melalui suntikan seperti vaksin BCG, DPT, Campak, dan melaliu mulut seperti Polio. Sehinga di harapka anak menjadi kebal terhadap penyakit tertentu (A.Aziz Alimul Hidayat, hal 101.). Pemberian imunisasi kadang menimbulkan efek samping. Rasa ketakutan terhadap vaksin menjadi lebih dominan di banding ketakutan terhadap penyakitnya. Efek samping vaksinasi ini di kenal sebagai kejadian ikutan pasca imunisasi (KIPI), timbul secara cepat maupun lambat dapat di bagi menjadi kelainan lokal, siskemik, reaksi susunan saraf, serta reaksi lainnya. Reaksi lokal di tandai dengan rasa nyeri dan bengkak kemerahan di tempat suntikan, serta demam atau ruam.

Sejak penetapan The Expanded Program On Imunisation (EPI) oleh World Health Organisation (WHO), cakupan imunisasi dasar bayi meningkat dari 5\% hingga mendekati $80 \%$ di seluruh dunia. Berdasarkan data terakhir WHO sampaisaat ini angka kematian bayi akibat penyakit infeksi yang seharusnya dapat di cegah dengan imunisasi masih terbilang tinggi. Berdasarkan data Ditjen PP \& PL Kemenkes RI, 2017 (update s.d 30 April 2017) menunjukkan 
bahwa di Provinsi Jawa Timur dengan cakupan masing-masing imunisasi adalah sebagai berikut BCG 98,4\%, HB0 94,8\%, DPT/HB1 53,5\%, DPT/HB3 60,3\%, Polio 4 $99,6 \%$, Campak 99,9\%. Berdasarkan data tersebut masih ada dua cakupan yang belum terpenuhi yang belum memenuhi target $\leq 80 \%$. Laporan penghitungan bayi yang telah mendapatkan imunisasi dasar lengkap di kabupaten sumenep sampai dengan bulan November 2017 sebanyak 11.692 atau $(81,70 \%)$ dengan jumlah bayi sebanyak 14.311, Kecamatan gapura merupakan kecamatan dengan cakupan imunisasi dasar lengkap kumulatif paling sedikit yaitu sebesar 20,31\% dengan jumlah bayi sebanyak 517 (Dinkes, 2015).

Pengambilan data awal yang di lakukan di Kecamatan Gapura kepada $10 \mathrm{ibu}$ yang mempunyai bayi 0-12 bulan, semua ibu tidak melengkapi imunisasi pada bayinya karena takut setelah di berikan imunisasi anak akan panas, menangis kesakitan, dan keadaanya melemah. Salah satu faktor penyebab tidak tercapainya imunisasi dasar lengkap karena banyak ibu di Desa Banjar Barat tidak melengkapi imunisasi karena takut akan efek yang terjadi setelah bayinya di berikan imunisasi misalnya panas, menangis kesakitan dan keadaan yang melemah. Beberapa penyebab di antaranya adalah kurangnya informasi, tingkat pendidikan dan persepsi terhadap imunisasi.

\section{METODE PENELITIAN}

Desain penelitian adalah sesuatu yang sangat penting dalam penelitian, yang memungkinkan pemaksimalan kontrol beberapa faktor yang bisa mempengaruhi akurasi suatu hasil. Desain penelitian merupakan suatu strategi penelitian dalam mengidentifikasi permasalahan sebelum perencanaan akhir pengumpulan data dan digunakan untuk mendefinisikan struktur dimana penelitaian dilaksanakan (Nursalam, 2013).

Desain penelitian yang digunakan dalam penelitian ini adalah Korelasional (hubungan dan asosiasi) dengan menggunakan pendekatan cross-sectional yaitu jenis penelitian yang menekankan pada waktu pengukuran atau observasi data variabel independen dan dependen hanya satu kali pada satu saat. Pada jenis ini variabel independen dan dependen dinilai secara simultan pada satu saat (Nursalam, 2013).

\section{HASIL DAN PEMBAHASAN}

1.1 Karakteristik Responden berdasarkan Umur

Tabel 1 Distribusi Frekuensi Ibu Yang Mempunyai Bayi Usia 0-12 Bulan Berdasarkan Umur di Desa Banjar Barat Tahun 2017.

\begin{tabular}{cccc}
\hline No & Umur (tahun) & f & \% \\
\hline 1 & $17-20$ & 4 & 11,4 \\
2 & $21-24$ & 16 & 45,7 \\
3 & $25-28$ & 10 & 28,6 \\
4 & $29-32$ & 5 & 14,3 \\
\hline & Jumlah & $\mathbf{3 5}$ & $\mathbf{1 0 0}$ \\
\hline
\end{tabular}

Sumber : Data Primer

Berdasarkan tabel 1 menunjukkan bahwa hampir setengahnya umur responden adalah 21-24 tahun sebanyak 16 Ibu (45,7\%).

\begin{tabular}{cccc} 
No & Kecemasan Ibu & f & \% \\
\hline 1 & Kecemasan berat & 1 & 2,9 \\
2 & Kecemasan sedang & 1 & 2,9 \\
3 & Kecemasan ringan & 22 & 62,8 \\
4 & Tidak cemas & 11 & 31,4 \\
\hline & Jumlah & $\mathbf{3 5}$ & $\mathbf{1 0 0}$ \\
\hline
\end{tabular}

1.2 Karakteristik Responden berdasarkan Pendidikan

Tabel 2 Distribusi Frekuensi Ibu Yang Mempunyai Bayi Usia 0-12 Bulan Berdasarkan Tingkat Pendidikan di Desa Banjar Barat Tahun 2017

\begin{tabular}{cccc}
\hline No & Pendidikan & f & \% \\
\hline 1 & Tidak Sekolah & 1 & $\mathbf{2 , 9}$ \\
2 & SD/MI & 17 & 48,6 \\
3 & SMP/MTs & 10 & 28,6 \\
4 & SMA/MA & 7 & 20 \\
\hline & Jumlah & $\mathbf{3 5}$ & $\mathbf{1 0 0}$ \\
\hline
\end{tabular}

Sumber : Data Primer

Berdasarkan tabel 5.2 menunjukkan bahwa hampir setengahnya pendidikan responden adalah SD/MI sebanyak 17 Ibu (54,3\%).

1.3 Karakteristik Responden berdasarkan
Pekerjaan

Tabel 3 Distribusi Frekuensi Ibu Yang Mempunyai Bayi Usia 0-12 Bulan 
Berdasarkan Pekerjaan di Desa Banjar Barat Tahun 2017

\begin{tabular}{cccc}
\hline No & Pekerjaan & $\mathbf{f}$ & $\mathbf{\%}$ \\
\hline 1 & Ibu rumah tangga & 7 & 20 \\
2 & Petani & 23 & 65,7 \\
3 & Wiraswasta & 5 & 14,3 \\
\hline & Jumlah & $\mathbf{3 5}$ & $\mathbf{1 0 0}$ \\
\hline
\end{tabular}

Sumber : Data Primer

Berdasarkan tabel 3 menunjukkan bahwa sebagian besar pekerjaan responden adalah petani sebanyak 23 Ibu $(65,7 \%)$.

\section{Data Khusus (Variabel Yang Diukur)}

1.4 Data Kecemasan Ibu

Tabel 4 Distribusi Frekuensi kecemasan ibu Tentang Imunisasi Dasar Lengkap di Desa Banjar Barat Tahun 2017.

\begin{tabular}{cccc}
\hline No & Kategori Kecemasan & (f) & \% \\
\hline 1 & Kecemasan berat & 1 & 2,9 \\
2 & Kecemasan sedang & 1 & 2,9 \\
3 & Kecemasan ringan & 22 & 62,8 \\
4 & Tidak cemas & 11 & 31,4 \\
\hline & Jumlah & $\mathbf{3 5}$ & $\mathbf{1 0 0}$ \\
\hline
\end{tabular}

Berdasarkan tabel 4 menunjukkan bahwa sebagian besar responden mengalami kecemasan ringan sebanyak $22 \mathrm{Ibu}(62,8 \%)$.

1.5 Data Pemberian Imunisasi Dasar Lengkap Tabel 5 Distribusi Frekuensi Pemberian Imunisasi Dasar Lengkap di Desa Banjar Barat Tahun 2017.

\begin{tabular}{cccc}
\hline \multicolumn{4}{c}{ Kategori } \\
\hline No & $\begin{array}{c}\text { Pemberian Imunisasi } \\
\text { Dasar Lengkap }\end{array}$ & f & \% \\
\hline $\mathbf{1}$ & $\begin{array}{c}\text { Lengkap sesuai } \\
\text { dengan usia }\end{array}$ & 16 & 45,7 \\
$\mathbf{2}$ & $\begin{array}{c}\text { Tidak Lengkap sesuai } \\
\text { dengan usia }\end{array}$ & 19 & 54,3 \\
\hline & Jumlah & $\mathbf{3 5}$ & $\mathbf{1 0 0}$ \\
\hline
\end{tabular}

Sumber : Data Primer

Berdasarkan tabel 5 menunjukkan bahwa sebagian besar responden tidak memberikan imunisasi dasar yang tidak lengkap pada bayinya sebanyak 19 Ibu $(54,3 \%)$.

1.6 Data Analisa Hubungan Kecemasan Ibu Dengan Pemberian Imunisasi Dasar Lengkap Pada Bayi Usia 0-12 Bulan di Desa Banjar Barat Tahun 2017

\begin{tabular}{|c|c|c|c|c|c|c|c|c|c|}
\hline \multirow{3}{*}{ No } & \multirow{3}{*}{$\begin{array}{c}\text { Kecemasan } \\
\text { ibu }\end{array}$} & \multicolumn{6}{|c|}{ Pemberian Imunisasi } & \multirow{3}{*}{$\mathbf{R}$} & \multirow{3}{*}{$\begin{array}{c}\mathbf{P} \\
\text { Value }\end{array}$} \\
\hline & & \multicolumn{2}{|c|}{ Tidak Lengkap } & \multicolumn{2}{|c|}{ Lengkap } & \multicolumn{2}{|c|}{ Total } & & \\
\hline & & $\mathbf{F}$ & $\%$ & $\mathbf{F}$ & $\%$ & $\mathbf{F}$ & $\%$ & & \\
\hline 1 & $\begin{array}{c}\text { Kecemasan } \\
\text { Berat }\end{array}$ & 1 & 2,9 & 0 & 0 & 1 & 2,9 & & \\
\hline 2 & $\begin{array}{l}\text { Kecemasan } \\
\text { sedang }\end{array}$ & 1 & 2,9 & 0 & 0 & 1 & 2,9 & & \\
\hline 3 & $\begin{array}{l}\text { kecemasan } \\
\text { ringan }\end{array}$ & 17 & 48,6 & 5 & 14,3 & 22 & 62,9 & 0,732 & 0,000 \\
\hline 4 & Tidak cemas & 0 & 0 & 11 & 31,4 & 11 & 31,4 & & \\
\hline & Total & 19 & 54,3 & 16 & 45,7 & 35 & 100 & & \\
\hline
\end{tabular}

Uji statistik yang digunakan untuk mengetahui Desa Banjar Barat kecamatan gapura tahun hubungan kecemasan ibu dengan pemberian imunisasi pada bayi usia 0-12 bulan di Desa Banjar Barat tahun 2017 adalah uji Korelasi Spearman dengan derajat kemaknaan 95\% ( $\alpha$ $=0,05)$. Distribusi frekuensi hubungan kecemasan ibu dengan pemberian imunisasi dasar lengkap pada bayi usia 0-12 bulan di Desa Banjar Barat Kecamatan GapuraTahun 2017 dapat diihat pada tabel 5.6.

Tabel 6 Distribusi Frekuensi Hubungan kecemasan ibu dengan pemberian imunisasi dasar lengkap pada anak usia 0-12 bulan di 2017. Hasil penyajian data pada tabel 6 di peroleh data dari 35 ibu yang memiliki bayi usia $0-12$ bulan yang tidak cemas pemberian imunisasi bayinya lengkap sebanyak $11 \mathrm{Ibu}$ $(31,4 \%)$, kecemasan ibu dengan kecemasan ringan pemberian imunisasi bayinya tidak lengkap sebanyak $17 \mathrm{ibu}$ (48,6\%), kecemasan ibu dengan kecemasan sedang pemberian imunisasi bayinya tidak lengkap sebanyak 1 Ibu $(2,9 \%)$, sedangkan ibu dengan kecemasan berat pemberian imunisasi bayinya tidak lengkap sebanyak $1 \mathrm{Ibu}(2,9 \%)$. 
Hasil uji statistik diperoleh $\mathrm{P}$ value $<\alpha(0,000$ $<0,05)$ dan tingkat kepercayaan 95\%, maka dapat disimpulkan bahwa terdapat hubungan yang signifikan antara kecemasan ibu dengan pemberian imunisasi pada bayi usia 0-12 di Desa Banjar Barat, yang artinya Ho ditolak, sedangkan H1 diterima. Kekuatan korelasi dapat dilihat melalui nilai $R$ yaitu 0,732 yang berarti bahwa kekuatan hubungan antar variabel sangat kuat.

1. Kecemasan Ibu Tentang Pemberian Imunisasi Dasar Lengkap Pada Bayi Usia 0-12 Bulan di Desa Banjar Barat

Tabel 4 menunjukkan bahwa sebagian besar ibu yang memiliki bayi usia 0-12 bulan dengan kecemasan ringan sebanyak $22 \mathrm{Ibu}(62,8 \%)$.

Menurut Hidayat (2005), Pemberian imunisasi pada bayi bertujuan agar tubuh kebal terhadap penyakit tertentu. Menurut Depkes (2000), Terdapat evek samping setelah pelaksanaan imunisasi yang di kenal dengan kejadian ikutan pasca imunisasi (KIPI) atau adverse evens following immunization (AEFI) merupakan kejadian sakit yang terjadi setelah menerima imunisasi yang di duga berhubungan dengan imuisasi.

Menurut Tecyya (2009), kebanyakan anak menderita panas setelah mendapatkan imunisasi DPT, tetapi itu adalah yang wajar, namun seringkali ibu-ibu tegang, cemas dan khawatir. Menurut (Hemas, 2007) banyak ibu yang cemas sekali karena timbul bengkak di bekas tempat suntikan, untuk anak yang memiliki riwayat kejang dan demam, imunisasi DPT tetap aman dan tidak membahayakan, tetapi banyak ibu yang cemas. Menurut Ani dan Ai (2009), adapun penyebab kecemasan ibu di karenakan pemberitaan miring tentang efek samping imunisasi.

Berdasarkan penelitinan yang di lakukan oleh Lynda M. Baker (2007) Pemahaman, persepsi dan pengetahuan ibu tentang imunisasi membantu pengembangan program kesehatan. Hal tersebut didukung oleh penelitian yang di lakukan oleh Mahmuda Dan Susilawati (2007) salah satu penyebab kecemasan ibu di sebabkan oleh tingkat pengetahuan.

Penelitian tersebut juga relevan dengan penelitian Hayana dkk (2013) pemberian imunisasi di pengaruhi oleh kecemasan ibu di sebabkan karna pengetahuan dan pendidikan mengenai evek samping dari munisasi itu sendiri.

2. Pemberian Imunisasi Dasar Lengkap Pada Bayi Usia 0-12 Bulan di Desa Banjar Barat

Tabel 5 menunjukkan bahwa sebagian besar responden memberikan imunisasi dasar yang tidak lengkap pada bayinya sebanyak $19 \mathrm{Ibu}$ (54,3\%). Menurut Suparyanto (2011) pemberian imunisasi dasar yang tidak lengkap karena dipengaruhi oleh beberapa faktor, diantaranya adalah tingkat pengetahuan ibu, kepercayaan, sikap, pendidikan, pekerjaan ibu, pendapatan/penghasilan, usia ibu, jarak pelayanan kesehatan, sarana dan prasarana kesehatan, pelayanan petugas kesehatan, dukungan keluarga dan kecemasan . Menurut Ani dan Ai (2009) adapun penyebab kecemasan ibu di karenakan pemberitaan miring tentang efek samping imunisasi. Jika dilihat dari ketidak lengkapan pemberian imunisasi di Banjar Barat, hal tersebut disebabkan karena berbagai faktor seperti rendahnya tingkat pendidikan, pengetahuan ibu, usia dan kecemasan ibu.

Berdasarkan tabel 1.1 menunjukkan bahwa hampir setengahnya umur responden adalah 21-24 tahun sebanyak 16 Ibu (45,7\%). Waldoeher (1997, dalam Reza, 2006, hlm.25) mengatakan bahwa status imunisasi semakin baik seiring dengan peningkatan usia ibu. Penelitian Rahma Dewi (1994) memperoleh hasil bahwa 58,3\% kelengkapan status imunisasi anak terdapat pada ibu yang berusia 20-29 tahun. Penelitian Wardhana (2001) disebutkan bahwa ibu yang berusia $\geq 30$ tahun cenderung untuk tidak melakukan imunisasi lengkap dibandingkan dengan ibu yang berusia $<30$ tahun cenderung untuk melakukan imunisasi lengkap 2,03 kali dibandingkan dengan usia $i b u \geq 30$ tahun.

Berdasarkan tabel 1.2 menunjukkan bahwa sebagian besar pendidikan responden adalah SD/MI sebanyak 17 Ibu $(48,6 \%)$.

Wardhana (2001, dalam Lienda, 2009, hlm.25) mengatakan bahwa pendidikan tinggi berkaitan erat dengan pemberian imunisasi pada anak. Sejalan dengan hal tersebut berdasarkan penelitian Idwar (2001) juga disimpulkan bahwa tingkat pendidikan seseorang ibu yang telah tinggi akan berpeluang besar untuk mengimunisasikan 
anaknya. Ibu yang berpendidikan mempunyai pengetahuan yang lebih baik tentang pencegahan penyakit dan kesadaran lebih tinggi terhadap masalah-masalah kesehatan yang sedikit banyak telah diajarkan disekolah. Hal ini diperkuat kembali dengan adanya penelitian oleh Widyanti (2008) menjelaskan bahwa ibu yang memiliki tingkat pendidikan yang telah tinggi akan memberikan imunisasi lebih lengkap kepada anaknya dibandingkan ibu dengan pendidikan rendah.

Berdasarkan tabel 1.3 menunjukkan bahwa sebagian besar pekerjaan responden adalah petani sebanyak 23 Ibu $(65,7 \%)$. Dapat disimpulkan bahwa kemungkinan pekerjaan ibu dapat mempengaruhi pemberian imunisasi.

\section{Kecemasan Ibu Dengan Pemberian}

Imunisasi Dasar Lengkap Pada Bayi Usia 0-12 Bulan di Desa Banjar Barat

Hasil penyajian data pada tabel 1.6 di peroleh data dari 35 ibu yang memiliki bayi usia 0-12 bulan yang tidak cemas pemberian imunisasi bayinya lengkap sebanyak $11 \mathrm{Ibu}$ $(31,4 \%)$, kecemasan ibu dengan kecemasan ringan pemberian imunisasi bayinya tidak lengkap sebanyak 17 ibu (48,6\%), kecemasan ibu dengan kecemasan sedang pemberian imunisasi bayinya tidak lengkap sebanyak 1 Ibu $(2,9 \%)$, sedangkan ibu dengan kecemasan berat pemberian imunisasi bayinya tidak lengkap sebanyak $1 \mathrm{Ibu}(2,9 \%)$.

Hasil uji statistik diperoleh $\mathrm{P}$ value $<\alpha(0,000<0,05)$ dan tingkat kepercayaan 95\%, maka dapat disimpulkan bahwa terdapat hubungan yang signifikan antara kecemasan ibu dengan pemberian imunisasi pada bayi usia 0-12 di Desa Banjar Barat, yang artinya Ho ditolak, sedangkan $\mathrm{H} 1$ diterima. Kekuatan korelasi dapat dilihat melalui nilai $\mathrm{R}$ yaitu 0 , 732 yang berarti bahwa kekuatan hubungan antar variabel sangat kuat. Menurut (Tecyya,2009) kebanyakan anak menderita panas setelah mendapatkan imunisasi DPT, tetapi itu adalah yang wajar, namun seringkali ibu-ibu tegang, cemas dan khawatir.

Penelitian ini sesuai dengan Hemas (2007) banyak ibu yang cemas sekali karena timbul bengkak di bekas tempat suntikan, untuk anak yang memiliki riwayat kejang dan demam, imunisasi DPT tetap aman dan tidak membahayakan, tetapi banyak ibu yang cemas. Mereka beranggapan imunisasi hanya akan membuat bayi panas, menangis kesakitan, terdapat ruam merah, dan keadaannya melamah, sehingga ibu-ibu memilih untuk menghentikan pemberian imunisasi bayinya. Setiap ada petugas kesehatan yang datang untuk memberikan imunisasi dasar lengkap para ibu cenderung tidak hadir dengan alasan sibuk bekerja, dan mengatakan di imunisasi dengan tidak di imunisasi sama saja samasama sakit juga.

\section{Kesimpulan}

Berdasarkan hasil penelitian yang telah diuraikan, maka peneliti mengambil kesimpulan:

1. Kecemasan Ibu tentang pemberian imunisasi dasar lengkap pada bayi usia 012 bulan di Desa Banjar Barat tahun 2017 sebagian besar mengalami kecemasan ringan.

2. Pemberian imunisasi dasar lengkap pada bayi usia 0-12 bulan di Desa Banjar Barat tahun 2017 sebagian besar memiliki status pemberian imunisasi yang tidak lengkap.

3. Terdapat hubungan kecemasan Ibu dengan pemberian imunisasi dasar lengkap pada bayi usia 0-12 Bulan di Desa Banjar Barat tahun 2017.

\section{Saran}

a. Bagi Masyarakat

Keluarga dan ibu diharapkan untuk ikut serta jika ada penyuluhan kesehatan mengenai imunisasi dasar lengkap dan banyak bertaya sebelum di lakukan pemberian imunisasi dasar lengkap, mengenai efek samping apa saja yang akan timbul setelah di lakukan pemberian imunisasi dasar lengkap tersebut..

b. Bagi Pelayanan Kesehatan

Tenaga kesehatan khususnya di UPT. Puskesmas Gapura memberiakan penyuluhan kesehatan mengenai pentingnya imunisasi dan lebih banyak melakukan penjelasan secara umum maupun personal.

c. Bagi Ilmu Keperawatan

Bagi ilmu keperawatan di harapkan bermanfaat untuk pengembangan maupun reverensi terhadap ilmu keperawatan khususnya keperawatan anak.

d. Bagi Penelitian Selanjutnya

Bagi penelitian selanjutnya diharapkan sebagai bahan perbandingan tentang hubungan kecemasan ibu dengan pemberian imunisasi 
dasar lengkap pada bayi usia 0-12 bulan di Desa Banjar Barat Kecamatan Gapura tahun 2017.

\section{DAFTAR PUSTAKA}

Alan R. Tumbelaka, Sri Rezeki S Hadinegoro. (2008). Difteria, Tetanus, Pertusis. Dalam IGN Ranuh, Hariyono Suyitno, Sri Rezeki S Hadinegoro, Cissy B. Kartasasmita, Ismoedijanto, Soedjatmiko : Pedoman Imunisasi di Indonesia. Edisi Ketiga. Jakarta : Ikatan Dokter Anak Indonesia

Ani.M."Hubungan Antara Tingkat Pengetahuan Ibu Tentang Imunisasi Polio Dengan Timgkat Kecemasan Pasca Imunisasi Polio Pada Anaknya Di Posyandu Margasari Tasikmalayatahun 2007" Fakultas Ilmu Keperawatan Universitas Indonesia : Jakarta

Carman Copel, Linda.(2007). psichiatric and mental healt care: nurses's clinical guide. Buku kedokteran ECG, hal 178.Edisi 2

Comer. (1992) dalam Videbeck, (2008). Pengertian Kecemasan.(Online) (http://Repository.usu.ac.id diakses tanggal 20 juni 2016)

Depkes RI. (2006). Profil Kesehatan Indonesia. Jakarta : Departemen Kesehatan RI

Depkes RI. (2009). Profil Kesehatan Indonesia. Jakarta : Departemen Kesehatan RI

Depkes RI. 2000. Pedoman pelayanan imunisasi. Jakarta Dinkes Prop Jatim

Dinkes, Sumenep. (2015). Cakupan Imunisasi di Kabupaten Sumenep. Sumenep : Dinkes Sumenep

Effendy. 2004. Dasar-dasar Kepewatan Kesehatan Masyarakat. Jakarta. EGC

Friedman, M. Marylin (1998). Keperawatan Keluarga : Teori dan Praktek. Jakarta : EGC

Hariyono, Suyitno. (2008). Poliomielitis. Dalam IGN Ranuh, Hariyono Suyitno, Sri Rezeki S Hadinegoro, Cissy B. Kartasasmita, Ismoedijanto, Soedjatmiko : Pedoman Imunisasi di Indonesia. Edisi Ketiga. Jakarta : Ikatan Dokter Anak Indonesia
Hariyono, Suyitno. (2008). Poliomielitis. Dalam IGN Ranuh, Hariyono Suyitno, Sri Rezeki S Hadinegoro, Cissy B. Kartasasmita, Ismoedijanto, Soedjatmiko : Pedoman Imunisasi di Indonesia. Edisi Ketiga. Jakarta : Ikatan Dokter Anak Indonesia

Hariyono, Suyitno. (2008). Poliomielitis. Dalam IGN Ranuh, Hariyono Suyitno, Sri Rezeki S Hadinegoro, Cissy B. Kartasasmita, Ismoedijanto, Soedjatmiko : Pedoman Imunisasi di Indonesia. Edisi Ketiga. Jakarta : Ikatan Dokter Anak Indonesia

Hawari. 2001. Cara penilaian kecemasan. (Online) (http://eprints.ung.ac.co.id, diakses pada 20 juni 2016)

Hayana, Dkk. (2013) faktor-faktor yang mempengaruhi tingkat kecemasan ibu sebelum pemberian imunisasi DPT pada bayi di wilayah kerja puskesmas samataring kabupaten sinjai. jurnal volume 2 nomor 6

Hidayat, Alimul Aziz. (2005). Pengantar Ilmu Keperawatan Anak 1. Jakarta : Salemba Medika

Hidayat, Alimul Aziz. (2008). Ilmu Kesehatan Anak Untuk Pendidikan Kebidanan. Jakarta : Salemba Medika

http://Repository.usu.ac.id diakses tanggal 20 juni 2016

Kemenkes, RI. (2014).Pusat Data dan Informasi. Jakarta : Kementrian Kesehatan RI

Lynda M. Baker. 2007. "Ibu Pengetahuan Dan Kebutuhan Informasi Berkaitan Dengan Imunisasi Anak”. Jurnal Faktor-Faktor Yang Mempengaruhi Tingkat Kecemasan Ibu Sebelum Pemberian Imunisasi DPT Pada Bayi Di Wilayah Kerja Puskesmas Samataring Kabupaten Sinjai. Volume 2 Nomor 6 Tahun 2013

Murwani. 2008. Pengertian kecemasan. (Online) (http://eprints.ung.ac.co.id, diakses pada 20 juni 2016)

Notoatmodjo (2007). Promosi Kesehatan dan Ilmu Perilaku. Jakarta : Rineka Cipta

Nugroho, Wahyudi. (2008).Keperawatan Gerontik Dan Geriatrik. Buku Kedokteran EGC, hal 122. Edisi 3 
Nursalam. (2013). Metodologi Penelitian Ilmu Keperawatan. Jakarta: Salemba Medika

Nursalam. (2014). Metodologi Penelitian Ilmu Keperawatan. Jakarta: Salemba Medika

Setiadi. (2008). Konsep dan Keperawatan Keluarga. Yogyakarta : Graha Ilmu

Sundeen, Stuart. 1998. Penyebab kecemasan. (Online) (http://eprints.ung.ac.co.id, diakses pada 20 juni 2016)

Suparyanto. (2011). Konsep Kelengkapan Imunisasi

Tecyya. 2009. Demam Sehabis Imunisasi. Jurnal Faktor-Faktor Yang Mempengaruhi Tingkat Kecemasan Ibu Sebelum Pemberian Imunisasi DPT Pada Bayi Di Wilayah Kerja Puskesmas Samataring Kabupaten Sinjai. Volume 2 Nomor 6 Tahun 2013

Videbeck,Sheila L.(2012).Nursing Instructor Des Moines Area Community Collage Ankeny, Lowa. Buku ajar keperawatan jiwa EGC, Hal 308

Wong, Donna L. (2003). Pedoman Klinis Keperawatan Pediatrik. Jakarta : EGC 